\title{
New Dystrophin/Dystroglycan interactors control neuron behavior in Drosophila eye
}

April K Marrone $^{1 \dagger}$, Mariya M Kucherenko ${ }^{1 \dagger}$, Valentyna M Rishko ${ }^{1,2+}$ and Halyna R Shcherbata ${ }^{1 *}$

\begin{abstract}
Background: The Dystrophin Glycoprotein Complex (DGC) is a large multi-component complex that is well known for its function in muscle tissue. When the main components of the DGC, Dystrophin (Dys) and Dystroglycan (Dg) are affected cognitive impairment and mental retardation in addition to muscle degeneration can occur. Previously we performed an array of genetic screens using a Drosophila model for muscular dystrophy in order to find novel DGC interactors aiming to elucidate the signaling role(s) in which the complex is involved. Since the function of the DGC in the brain and nervous system has not been fully defined, we have here continued to analyze the DGC modifiers' function in the developing Drosophila brain and eye.

Results: Given that disruption of Dys and Dg leads to improper photoreceptor axon projections into the lamina and eye neuron elongation defects during development, we have determined the function of previously screened components and their genetic interaction with the DGC in this tissue. Our study first found that mutations in chif, CG34400, Nrk, Lis1, capt and Cam cause improper axon path-finding and loss of SP2353, Grh, Nrk, capt, CG34400, vimar, Lis 1 and Cam cause shortened rhabdomere lengths. We determined that Nrk, mbl, capt and Cam genetically interact with Dys and/or Dg in these processes. It is notable that most of the neuronal DGC interacting components encountered are involved in regulation of actin dynamics.

Conclusions: Our data indicate possible DGC involvement in the process of cytoskeletal remodeling in neurons. The identification of new components that interact with the DGC not only helps to dissect the mechanism of axon guidance and eye neuron differentiation but also provides a great opportunity for understanding the signaling mechanisms by which the cell surface receptor Dg communicates via Dys with the actin cytoskeleton.
\end{abstract}

\section{Background}

Muscular dystrophies (MDs) are a group of diseases that are characterized by progressive muscular degeneration and concomitant loss of muscular strength ultimately leading to skeletal muscle deterioration and cardiac and/ or respiratory failure [1-3]. In addition, MDs are often associated with brain defects. Based upon the clinical symptoms of MDs they are categorized into various subtypes and currently no cures or preventions exist for these diseases, making them a worthwhile field of research. The most severe form of MD is Duchenne MD (DMD), an X-linked fatal disorder that afflicts approximately 1 out of every 3,500 males worldwide.

\footnotetext{
* Correspondence: halyna.shcherbata@mpibpc.mpg.de

† Contributed equally

'Max Planck Institute for biophysical chemistry, Research group of Gene Expression and Signaling, Am Fassberg 11, 37077, Goettingen, Germany Full list of author information is available at the end of the article
}

The DMD pathology contains a subset of individuals (about 1 in 3 ) that suffer from cognitive impairment and mental retardation, and these attributes of the disease appear to be independent from the muscular handicap $[4,5]$.

DMD arises from the loss of the Dystrophin (Dys) protein product, which provides a link between cytoskeletal actin and the ECM via the glycoprotein Dystroglycan (Dg). Dys binds Dg along with several other transmembrane proteins (two syntrophins, two dystrobrevins, and four sarcoglycans) [6,7] to assemble the Dystrophin Glycoprotein Complex (DGC).

Mutations of Dystroglycan, the key transmembrane component of the DGC, lead to discontinuities in the basement membrane surrounding the cerebral cortex and disorganized cortical layering (for review see [8]). In addition, Dg hypoglycosylation leads to congenital muscular dystrophies (CMDs), of which some feature brain 
defects including cobblestone (type II) lissencephaly. This type of lissencephaly is characterized by heterotopic glia and neurons that disrupt the laminar organization of the cerebral cortex [9], and mutations in glycosyltransferases that act upon $\alpha$-Dg have been linked to these disorders [10-18].

Disruption of the DGC not only affects cerebral cortex layering and lamina organization but also leads to physiological defects in neuron function. DMD patients and $m d x^{\mathrm{Cv} 3}$ (DMD mouse model missing the 427 and $70 \mathrm{kD}$ isoforms of Dys) and Dystroglycan knockout mice have reduced b-wave amplitudes in electroretinograms [19-22] supporting its specific role in the nervous system establishment and function. While the role of the DGC in muscle has been intensively studied, its function in the brain and nervous system has not been completely defined.

Drosophila has been demonstrated to serve as a useful model for studying the DGC in vivo since DGC mutants develop symptoms similar to MD patients [23-25]. Key human and Drosophila DGC components are evolutionarily conserved and interact in a similar manner [24,26,27]. As in mammals, in Drosophila proteins of the DGC are not only found at the muscle sarcolemma but also at the neuromuscular junction and in the PNS and CNS [23-25,28-32]. In the Drosophila brain Dg is expressed in R cells, glia and neurons, indicating that this protein has an important role in nervous system function [24,33,34]. Drosophila $\mathrm{R}$ cells provide an excellent system in which to study axon guidance, growth and elongation, negative and attractive guidance cues and neuron polarity establishment that later results in cell shape rearrangement. Both Dys and Dg affect photoreceptor cell elongation and are required in neurons and glia for proper photoreceptor axon migration $[24,33]$. Based on these phenotypes we performed a genetic interaction screen in order to find novel neuronal DGC components. We analyzed potential interactors that were identified in a previous screen to interact with Dys and/or Dg in muscle degeneration [35] and have found new components that interact with primarily Dys and to a lesser extent Dg in developing eye neurons. Among them are the calcium binding protein Calmodulin (Cam), Neurospecific receptor kinase (Nrk), a splicing factor Muscleblind (Mbl) and the actin recycling protein Capulet (Capt). Since most of these proteins have been shown to affect actin organization, polymerization and recycling, these results suggest that in neurons the DGC is involved in the processes of actin cytoskeleton regulation.

\section{Results}

Dys and Dg are expressed in Drosophila larval and adult nervous system

In this study we used antibodies that specifically recognize Dys and Dg proteins in order to detect the expression pattern of the main DGC components in the larval and adult nervous system. Previously it has been shown that Dg is expressed in neurons and glia in the larval Drosophila brain; high levels of Dg were detected in axons of photoreceptor sensory neurons, in the optic stalk, and in glial cells in the optic lobes [24]. Now we show that Dg is also expressed in the neuropile of $3^{\text {rd }}$ instar larval CNS and in three symmetric clusters at the lateral sides of the neuropile (Figure 1A). As expected, we observed a similar expression pattern for Dg's binding partner Dys (Figure 1C-D). The carboxy terminal specific Dys antibody that recognizes all isoforms [28], localizes in the neuropile, the optic lobes and in the axons of photoreceptor sensory neurons (Figure 1C). In accord with previously reported data [30], a strong Dys signal was detected in the neuropile and in the optic lobes when using an antibody that recognizes the CNSspecific Dp186 isoform (Figure 1D). In the adult Drosophila brain Dg is detected in the medulla and the lamina (Figure 1F-G) and a strong Dg signal is also seen in the retina (Figure 1F-). Dys expression in the adult brain appears to be localized to the lamina (Figure 1I). Dys and Dg are not only expressed in the CNS, but also the PNS (Figure $1 \mathrm{~K}-\mathrm{L}$ ): Dg staining was seen in and around the motoneurons (Figure $1 \mathrm{~K}$ ), while the Dys signal was overlaid with neuronal 22C10 staining (Figure 1L). In $D g$ and Dys loss-of-function homozygous mutants ( $D g^{\mathrm{O} 86}$ and $\left.D y s D f\right) \mathrm{Dg}$ and Dys signals were diminished (Figure 1B, E, J) implying that the detected expression pattern was specific in accord with previous reports for these antibodies [24,28,35]. A definite expression pattern for Dys and Dg in the Drosophila nervous system implies that the DGC is involved in nervous system development. As has been shown previously, disruption of Dys or Dg gives rise to a disorganized lamina plexus, and these two components genetically interact [24]. This abnormal photoreceptor guidance can result from growth cone malfunction, compromised cell polarity, malformed actin cytoskeleton or disrupted glia-neuron communication. During Drosophila development, eye discs contain ommatidia and photoreceptor neurons that project axons down the optic stalk to innervate the brain. For each ommatidia there are eight photoreceptors (R-cells), where six of the eight cells stop at the superficial lamina forming the lamina plexus, and the other two photoreceptors project further into the medulla. Later, during pupation photoreceptors differentiate and undergo morphological changes including elongation and Dys and Dg both affect this process [24,33]. Since recently we identified genes that interact with Dys and/or Dg in age related muscle degeneration [35], in the present work we analyzed these gene candidates for their involvement together with the DGC in neuron behavior during Drosophila visual system development. 


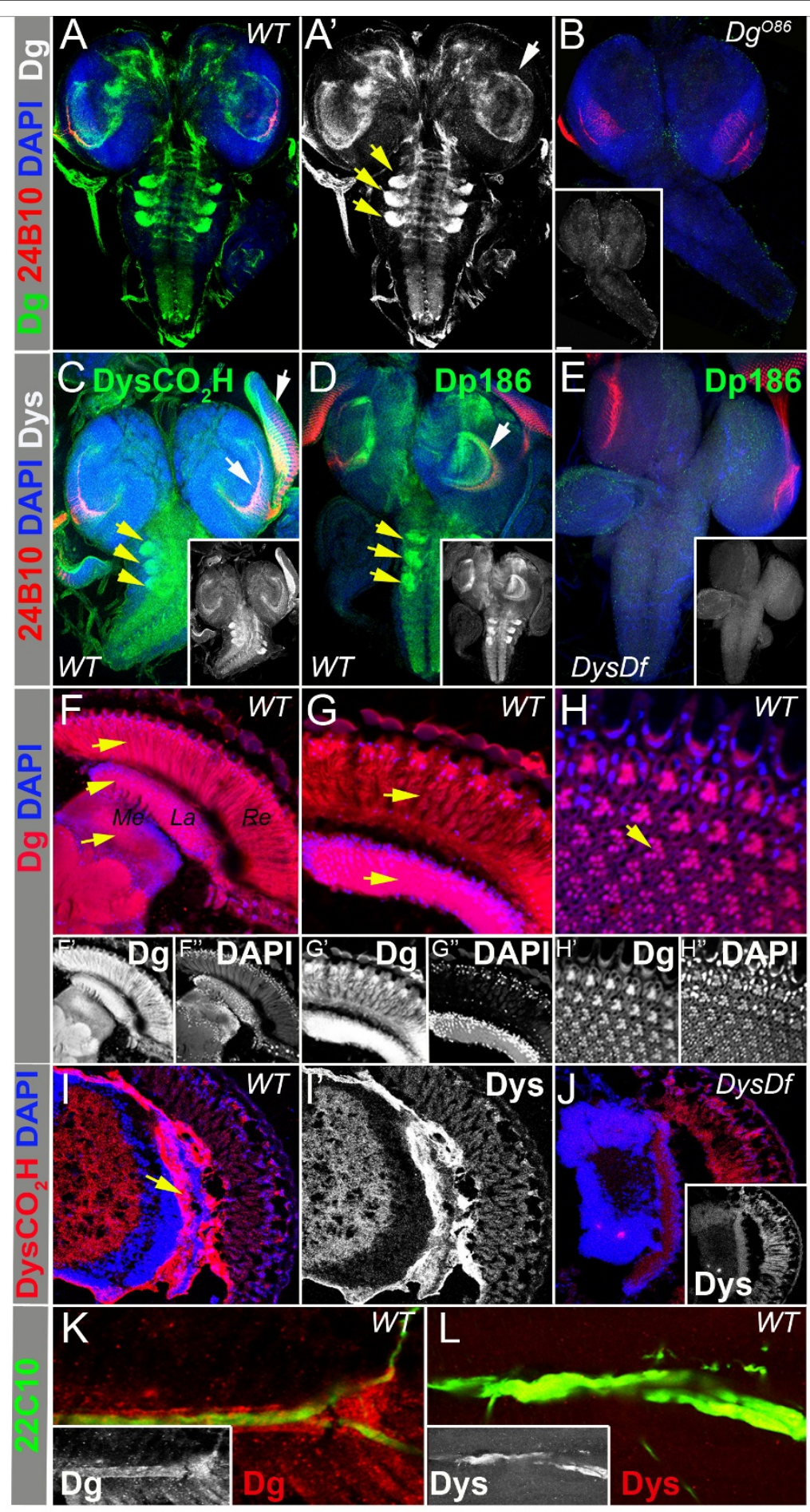

Figure 1 Dys and Dg are expressed in Drosophila larval and adult nervous systems. Expression pattern for Dg (A-B) and Dys (C-E) in Drosophila 3rd instar larval brains. Photoreceptor neurons are marked with the 24B10 antibody (red). The Dys antibody that recognizes all Dys isoforms by targeting the carboxy terminus shows localization in the brain and the eye discs (C) whereas an antibody that recognizes the Dp186 isoform is present only in the brain (D). Dg (B) and Dys (E) staining is absent in Dg and Dys loss-of-function homozygous mutants respectively. White arrows indicate Dys and Dg signal in the optic lobes and yellow arrows show staining in clusters at the lateral sides of the neuropile. The expression pattern for Dg (F-H) and Dys (I) in the adult brain. Arrows show strong Dg and Dys signals detected in the lamina (La) and medulla (Me) and Dg expression is also seen in the retina (Re). Dys staining is diminished from the brain of Dys loss-of-function homozygous mutant (J). Expression pattern for $\mathrm{Dg}(\mathrm{K})$ and Dys $(\mathrm{L})$ in Drosophila motorneurons marked with the 22C10 antibody (green). 
Muscle DGC-interacting components also affect photoreceptor axon guidance and rhabdomere length First, we questioned if previously identified DGC-interacting components have a role in neuronal architecture. Analysis of the $24 \mathrm{~B} 10$ staining pattern in $3^{\text {rd }}$ instar larvae found a significantly increased frequency of axon migration abnormalities in the brains of seven of the sixteen analyzed mutants (Calmodulin ( $\mathrm{Cam}$ ), Capulet (capt), Neurospecefic receptor kinase (Nrk), Chiffon (chif), CG34400, Lissencephaly-1 (Lis1) and Roundabout (robo) $)-22-47 \%$ in comparison to less than $10 \%$ observed in control animals (Figure 2A, Table 1), resulting in lamina plexus breaks or overgrown axons (Figure 2D-E). Next we asked if the DGC interactors are required to provide proper photoreceptor differentiation via analysis of adult brain histological sections. We used RNAi transgenic mutants crossed to GMR-Gal4 to target gene expression specifically in the visual system and identified shorter rhabdomeres in Cam, capt, Nrk, mbl, CG34400, Lis1, Visceral mesodermal armadillo repeats (vimar), SP2353 and Grainyhead (Grh) (Figure 2B, F-K, Table 1). Interestingly, we also noticed vacuoles in the retinas of $M b l^{R N A i} / G M R-G a l 4$ and Lis1 $1^{R N A i} / G M R$-Gal4 mutants (Figure 2G-H).

Mutations in many of the DGC-interacting genes cause visual system defects; therefore, we analyzed the expression of these genes in the Drosophila nervous system via examination of published data and available GFP expression lines. Lis1 mRNA was found in the brain hemispheres and eye imaginal discs of $3^{\text {rd }}$ instar larvae [36]. $\mathrm{Mbl}$ is also expressed in larval eye discs and is required for photoreceptor differentiation and $m b l$ deficiency results in shortened rhabdomeres [37]. In addition, expression in the central and peripheral nervous system has been shown for Grh [38], Nrk [39], Vimar [40] and Robo [41]. Interestingly, Robo is a transmembrane receptor for the extracellular matrix protein Slit, and previous reports showed that robo mutation results in improper axon crossing in the embryo and defects in compartmentalization of visual centers in the larval and adult brain [42-44].

We used modENCODE temporal expression data [45] to determine the expression of chif, CG34400 and SP2353. Expression of SP2353 is enriched in the adult brain and thoracic-abdominal ganglion. CG34400 and chif are expressed during development and adulthood and a previous report showed that chif mutants have a rough eye phenotype [46].

We also used GFP trap lines to recognize the expression pattern for Cam and Capt in the larval brain. We identified that Capt is expressed ubiquitously in the central and ventral brain and its expression is enriched in optic lobes and eye discs (Figure 2L-M). Cam has a more defined expression pattern in the neuropile and central brain and is also enhanced in optic lobes and eye discs (Figure $2 \mathrm{~N}-\mathrm{O}$ ). Capt and Cam are expressed in $\mathrm{R}$ cells of the eye disc (Figure 2M,O) and enriched in the area where R1-6 axons terminate, similarly to Dys and Dg suggesting that they may act in the same cell types (Figure $1 \mathrm{~A}, \mathrm{C})$. Since many of the proteins that interact with the DGC in muscle are expressed in the nervous system and have comparable phenotypes in the visual system to Dys and $D g$ mutants, we determined if they genetically interact with Dys and $D g$ in this tissue as well.

\section{Search for Dys and/or Dg interacting partners in photoreceptor axon pathfinding}

First we looked at photoreceptor axon pathfinding to assess the genetic interaction of Dys and $D g$ with components shown to be required in visual system neurons. For genetic analysis we used loss-of-function mutants for Dys and $D g$ that in homozygous and heterozygous state demonstrate breaks in the lamina plexus (Figure 3A-B). Since reduction of one copy of $D y s$ or $D g$ has a mild phenotype (Figure 3C-D), they can be used for a transheterozygous genetic interaction analysis in photoreceptor cell projections. Deleting one copy of an interacting gene in the heterozygous $D g$ or Dys mutant background will increase the frequency of abnormal lamina plexuses if there is a genetic interaction. Seven genes were found to increase the appearance of abnormal lamina plexuses in a Dys heterozygous background and three in a $D g$ heterozygous background (Figure 3C-D, Table 2). To avoid an additive effect, we tested the found interactors for a dominant phenotype. Three genes, Lis1, CG34400 and Grh have abnormal lamina plexuses while reduced by one copy (37.5\%, 14.3\% and 10.0\% respectively) and were therefore not considered to interac. In summary, in this screen we have identified Nrk - a protein with tyrosine kinase activity, Cam - a main player in calcium-mediated signaling, $\mathrm{Mbl}$ - a DNA binding protein implicated in mRNA splicing, and Capt - a factor required to prevent actin filament polymerization.

\section{Genetic interaction with Dys and Dg in controlling rhabdomere elongation}

To complement the data derived from analysis of $3^{\text {rd }}$ instar larval brains, we have performed a separate assay to evaluate the genetic interaction with the DGC in the process of rhabdomere (photoreceptor cell) elongation. First, we analyzed histological sections of Drosophila adult eyes and showed that Dys and $D g$ loss-of-function mutants also have shortened rhabdomeres, and reduction by one copy of both $D y s$ and $D g$ results in a genetic interaction (Figure 4A). Next we found that Cam and capt genetically interact with Dys 

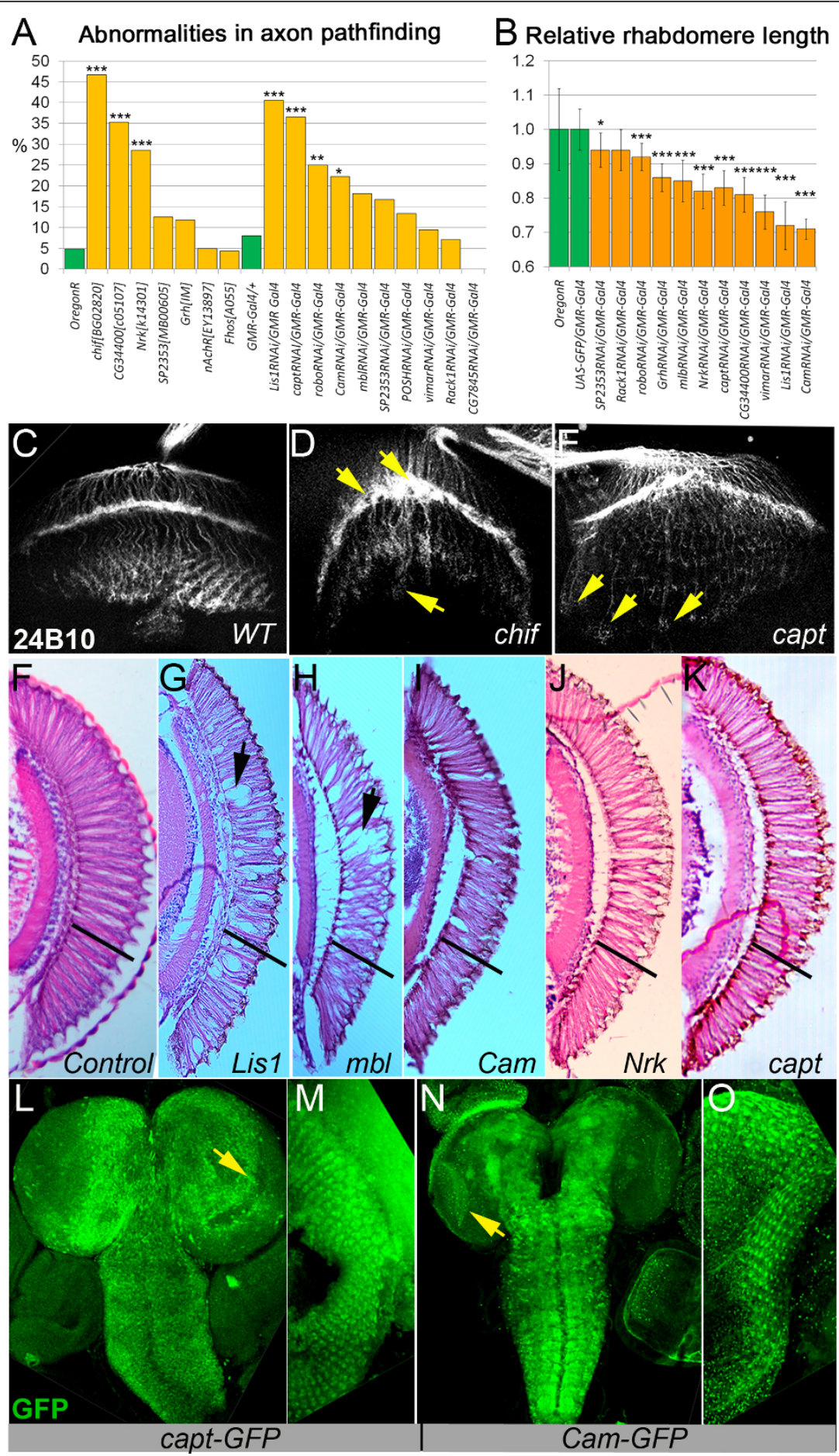

Figure 2 Requirement of screened components for photoreceptor cell development. (A) Bar graph represents frequency of defective photoreceptor axon projections in $3^{\text {rd }}$ instar larval brain. Statistics were determined using the $\chi^{2}$-test with Yate's correction where ${ }^{* * *} p \leq 0.001$, ${ }^{* *} p \leq 0.01,{ }^{*} p \leq 0.05$. (B) Bar graph shows relative rhabdomere length in adult flies with down regulation of tested components. Statistics were determined using a one-tailed Student's t-test where ${ }^{* * *} p \leq 0.001,{ }^{* *} p \leq 0.01,{ }^{*} p \leq 0.05$. (C) Photoreceptor axons projection in wild type $3^{\text {rd }}$ instar larval brain visualized with the 24B10 antibody. (D-E) Abnormal R cells growth and termination in $3^{\text {rd }}$ instar larvae with down regulated Chif and Capt (chif ${ }^{B G 02820}$, capt $^{\text {RNAi }} / G M R$-Gal4). Arrows indicate irregular axon termination in the lamina plexus, lamina plexus breaks and sites of overgrown axons. (F-K) Exemplary brain sections represent rhabdomere length and morphology in tested mutants in comparison to control (F). Arrows show vacuoles in retina and black bars indicate wt rhabdomere length. (L-O) capt and Cam GFP trap lines show expression patterns for Cam and Capt in the larval brain. (M, O) Enlarged view of eye discs. Arrows indicate expression pattern in optic lobes. 
Table 1 Genetic interactors of Dys and $D g$ in muscle have photoreceptor axon pathfinding defects and shortened rhabdomeres

\begin{tabular}{|c|c|c|c|c|c|c|}
\hline Genotype & $\begin{array}{l}\text { Defective lamina } \\
\text { plexuses (\%) }\end{array}$ & $\begin{array}{c}\mathrm{n} \text {, analyzed optic } \\
\text { lobes }\end{array}$ & $\chi^{2}$-value & $\begin{array}{l}\text { Relative rhabdomere } \\
\text { length }\end{array}$ & $\begin{array}{c}\mathrm{n} \text {, analyzed } \\
\text { eyes }\end{array}$ & p-value \\
\hline OregonR (Control) & 4.9 & 41 & & $1.0 \pm 0.12$ & 8 & - \\
\hline CG34400[C05107] & 35.3 & 17 & $21.7 * * *$ & - & - & - \\
\hline chif[BG02820] & 46.7 & 15 & $28.4 * * *$ & - & - & - \\
\hline Fhos[A055] & 4.3 & 23 & $3.3 \times 10^{-2}$ & - & - & - \\
\hline Grh[IM] & 11.8 & 17 & 2.1 & - & - & - \\
\hline$n A c R \alpha-30 D[E Y 13897]$ & 5.0 & 40 & $6.5 \times 10^{-2}$ & - & - & - \\
\hline Nrk[k14301] & 28.6 & 14 & $15.5 * * *$ & - & - & - \\
\hline SP2353[MB00605] & 12.5 & 32 & 2.6 & - & - & - \\
\hline eyeFlpFRT/Lis1FRT & - & - & - & $0.94 \pm 0.08$ & 10 & 0.20 \\
\hline GMR-Gal4/+ & 8.0 & 25 & - & $1.00 \pm 0.06$ & 32 & - \\
\hline $\mathrm{Cam}^{R N A i} / G M R-G a l 4$ & 22.2 & 18 & $5.8^{*}$ & $0.71 \pm 0.03$ & 6 & $1.3 \times 10^{-12 * * * *}$ \\
\hline${ }^{2} \mathrm{capt}^{\text {RNAi }} / \mathrm{GMR}$-Gal4 & 36.6 & 71 & $17.1 * * *$ & $0.81 \pm 0.03$ & 18 & $2.9 \times 10^{-11 * * *}$ \\
\hline${ }^{3} \mathrm{capt}^{R N A i} / \mathrm{GMR}-\mathrm{Gal} 4$ & 42.9 & 49 & $22.6^{* * *}$ & $0.76 \pm 0.07$ & 18 & $1.0 \times 10^{-14 * * *}$ \\
\hline$C G 7845^{R N A i} / G M R-G a l 4$ & 0.0 & 13 & 6.1 & - & - & - \\
\hline Fkbp $13^{R N A i} / G M R-G a l 4$ & 4.7 & 21 & 6.1 & - & - & - \\
\hline Lis $1^{R N A i} / G M R-G a l 4$ & 40.6 & 32 & $20.5 * * *$ & $0.72 \pm 0.07$ & 18 & $1.8 \times 10^{-11 * * *}$ \\
\hline$m b^{R N A i} / G M R-G a l 4$ & 18.2 & 22 & 3.2 & $0.85 \pm 0.06$ & 10 & $1.4 \times 10^{-7 * * *}$ \\
\hline $\mathrm{POSH}^{\text {RNAi} / G M R-G a l 4}$ & 13.3 & 15 & 0.9 & - & - & - \\
\hline Rack1 RNAi/GMR-Gal4 & 7.1 & 14 & $6.6 \times 10^{-4}$ & $0.94 \pm 0.06$ & 11 & 0.13 \\
\hline robo ${ }^{R N A i} / G M R-G a l 4$ & 25.0 & 20 & $7.8 * *$ & $0.92 \pm 0.04$ & 6 & 0.14 \\
\hline SP2353 RNAi /GMR-Gal4 & 16.7 & 12 & 2.4 & $0.94 \pm 0.05$ & & $0.014^{*}$ \\
\hline$N r^{R N A i} / G M R-G a l 4$ & - & - & - & $0.82 \pm 0.05$ & 14 & $3.8 \times 10^{-11 * * * *}$ \\
\hline CG34400 RNAi/GMR-Gal4 & - & - & - & $0.81 \pm 0.05$ & 17 & $2.0 \times 10^{-9 * * *}$ \\
\hline $\mathrm{Grh}^{\text {RNAi} / G M R-G a l 4 ~}$ & - & - & - & $0.86 \pm 0.04$ & 6 & $1.1 \times 10^{-4 * * * *}$ \\
\hline $\operatorname{vimar}^{R N A i} / G M R-G a l 4$ & 9.5 & 21 & 1.0 & $0.76 \pm 0.05$ & 13 & $2.2 \times 10^{-15 * * *}$ \\
\hline$P g k^{R N A i} / G M R-G a l 4$ & - & - & - & $0.77 \pm 0.04$ & 18 & $4.2 \times 10^{-6 * * * *}$ \\
\hline
\end{tabular}

all mutant alleles were obtained from BDSC, all RNAi mutants - from VDRC, ${ }^{1}$ - from DGRC

${ }^{2}$ Vienna stock number v21995

${ }^{3}$ Vienna stock number v101588

(Figure 4B, E-F, Table 3) and Cam, capt and mbl with $D g$ (Figure 4C, Table 3) displaying significantly shortened rhabdomeres. None of the tested mutants in a heterozygous state showed a significant phenotype $(1.04 \pm 0.05,0.97 \pm 0.02,1.03 \pm 0.06,1.00 \pm 0.02$ and $1.04 \pm 0.04$ for capt, Nrk, mbl, Lis1 and Cam respectively when normalized to $w t$ control).

Here we have found genes that interact with $D y s$ and/or $D g$ in axon pathfinding and in the process of photoreceptor cell elongation. Shortened rhabdomeres can result from actin cytoskeletal defects, but also from improper photoreceptor cell fate specification, retinal degeneration or abnormal innervations. Dynamic changes in actin filaments provide cell shape and control photoreceptor cell differentiation in developing Drosophila pupae. Therefore disruption of these processes may also affect the rhabdomere elongation in the Drosophila adult eye.
The DGC coordinates actin cytoskeleton remodeling

In our screen we identified Cam, Capt and $\mathrm{Mbl}$ as DGC-interacting partners that have roles in actin dynamics (Figure 5A), which implies that the phenotypes observed in the DGC mutants might at least partially result from improper actin cytoskeleton organization. To explore this hypothesis we generated clones in developing Drosophila eye discs homozygous for $D g$ loss-of-function alleles using the FLP/FRT system. These clones resulted in irregular ommatidia in adult animals (Figure 5B-C). For detailed characterization of this phenotype we performed immunohistochemical analysis of clonal pupal retinas using multiple cell markers including actin (Figure 5D-F). First we noticed that clones (marked by absence of GFP) have shortened ommatidia (Figure 5D-F, yellow bars). Further analysis revealed that there was also disrupted 

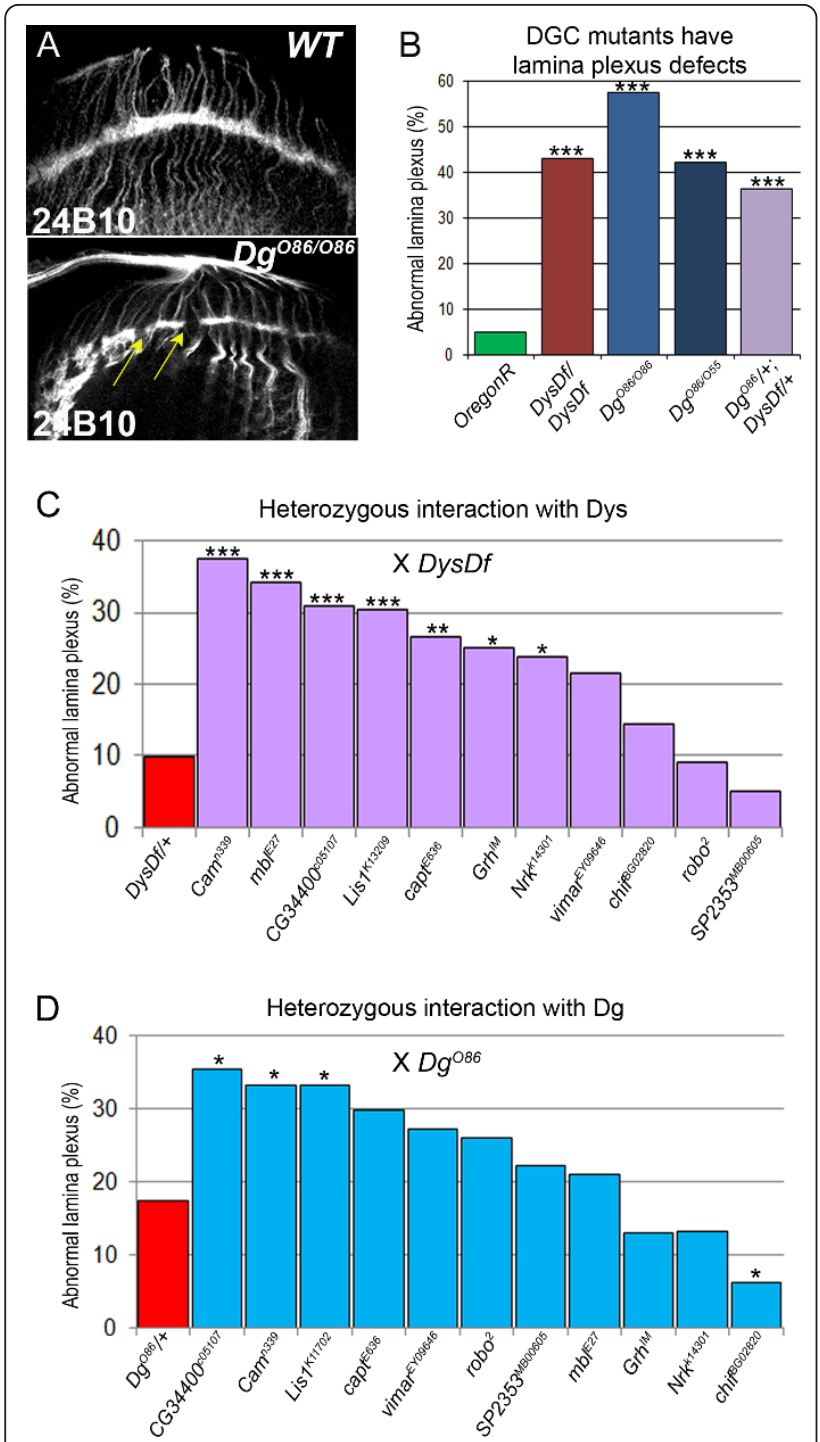

Figure 3 Genetic interactors were found to cause lamina plexus defects with Dys and Dg. (A) Wild type properly formed lamina plexus and defects found in Dg (and Dys) mutants showing gaps in the axon projections (arrows). 24B10 antibody was used to visualize photoreceptor axons. (B) Dys and Dg homozygous mutants have a significantly higher percentage of these defects from control and genetically interact. (C) Genetic interactions found with Dys, and with $D g(D)$. Statistics were determined using the $\chi^{2}$-test with Yate's correction where ${ }^{* *} p \leq 0.001,{ }^{* *} p \leq 0.01,{ }^{*} p \leq 0.05$.

layering of nuclei. DAPI staining made clear that nuclear migration during development does not occur properly, resulting in disorganized layers (Figure 5 EF). We also observed a different pattern of $\beta$-catenin (Arm) in clonal areas compared to wild type (Figure 5E-F) suggesting that during development cells lacking Dg cannot change their shape and elongate properly. In addition, irregular Actin was seen in $D g$ mutant clones indicating DGC involvement in actin dynamics in photoreceptor cells. This result suggests that the DGC cell autonomously coordinates actin cytoskeleton remodeling, the process required for proper photoreceptor cell growth and elongation, as well as axon migration during Drosophila eye development; it further indicates that photoreceptor axon pathfinding and $\mathrm{R}$-cell elongation defects observed in DGC mutants might be a result of improper actin reorganization during development.

\section{Discussion}

The roles that Dys and Dg play in disease have been apparent for some time since their disruption or misregulation has been closely linked to various MDs. Dg depletion results in CMD-like brain malformations associated with layering defects and aberrant neuron migration [34]. These defects arise due to extracellular matrix protein affinity problems that influence neuronal communication and result in learning and memory defects. Similar to brain layer formation, the migration of R1-R6 growth cones into the lamina occurs in a similar manner where glia cells that migrate from progenitor regions into the lamina provide a termination cue to innervating axons. In Drosophila Dys and Dg are expressed in the CNS, PNS and visual system and both proteins are required for proper photoreceptor axon guidance and rhabdomere elongation [24,33]. In this work we identified novel components implicated in the process of eyeneuron development. Moreover, we found that Nrk, $\mathrm{Mbl}$, Cam and Capt genetically interact with Dys and/or Dg in visual system establishment.

The proteins Mbl, Capt, Cam, Robo, Lis1 and Nrk have been shown previously to be associated with the nervous system, and now we have additionally found that mutations in chif, SP2353, CG34400 and vimar cause abnormal photoreceptor axon pathfinding and/or differentiation phenotypes. Lis1 has been shown to bind microtubules in the growth cone [47], and the human Lis1 homologue is important for neuronal migration and when mutated causes Lissencephaly, a severe neuronal migration defect characterized by a smooth cerebral surface, mental retardation and seizures [48]. Now we have found that $L i s 1^{R N A i} / G M R$-Gal4 mutants have abnormally formed lamina plexuses, shortened rhabdomeres, and retinal vacuoles. Chif has been shown to regulate gene expression during egg shell development and is related to a DNA replication protein in yeast [46]. The human ortholog for SP2353 (AGRN) is involved in congenital MD development [49,50]. Drosophila SP2353 is a novel agrin-like protein that contains Laminin G domains, which makes it a potential new extracellular binding partner for Dg. CG34400 encodes for a protein homologues to human DFNB31 (Deafness, autosomal recessive 31 ) that causes congenital hearing impairment 
Table 2 Genetic interaction with Dys and $D g$ in photoreceptor axon path finding

\begin{tabular}{|c|c|c|c|c|c|c|c|c|c|}
\hline $\begin{array}{l}\text { Gene } \\
\text { name }\end{array}$ & $\begin{array}{c}\text { Defective } \\
\text { lamina plexuses } \\
\text { (\%) }\end{array}$ & $\begin{array}{l}\mathrm{n} \text {, analyzed } \\
\text { optic lobes }\end{array}$ & $\chi^{2}$-value & $\begin{array}{c}\text { Defective } \\
\text { lamina plexuses } \\
\text { (\%) }\end{array}$ & $\begin{array}{l}n \text {, analyzed } \\
\text { optic lobes }\end{array}$ & $\chi^{2}$-value & $\begin{array}{c}\text { Defective } \\
\text { lamina plexuses } \\
\text { (\%) }\end{array}$ & $\begin{array}{l}\text { n, analyzed } \\
\text { optic lobes }\end{array}$ & $\chi^{2}$-value \\
\hline & DysDf $\mathrm{x}$ & DysDf $\mathrm{x}$ & DysDf $\mathrm{x}$ & $D g^{086} \mathrm{x}$ & $D g^{086} \mathrm{x}$ & $D g^{086} \mathrm{x}$ & OregonR $\mathrm{x}$ & Oregon $R \mathrm{x}$ & $\begin{array}{c}\text { OregonR } \\
\mathrm{x}\end{array}$ \\
\hline OregonR & 9.8 & 61 & $1.1^{\circ}$ & 17.5 & 40 & $6.0^{\circ *}$ & 4.9 & 41 & - \\
\hline DysDf & 42.9 & 49 & $28.8^{\circ} * * *$ & 36.4 & 55 & $22.5^{\circ} * * *$ & 9.8 & 61 & $1.1^{\circ}$ \\
\hline $\mathrm{Dg}[086]$ & 36.4 & 55 & $22.5^{\circ} * * *$ & 57.5 & 40 & $42.7^{\circ} * * *$ & 17.5 & 40 & $6.0^{\circ} *$ \\
\hline $\mathrm{Dg}[\mathrm{O55}]$ & - & - & - & 42.1 & 19 & $27.9^{\circ} * * *$ & - & - & - \\
\hline Cam[n339] & 37.5 & 48 & $15.0 * * *$ & 33.3 & 39 & $4.3 *$ & 0.0 & 9 & 3.0 \\
\hline Capt[E636] & 26.7 & 45 & $6.9 * *$ & 29.8 & 47 & 2.7 & 2.9 & 35 & 0.1 \\
\hline $\begin{array}{l}\text { CG34400 } \\
\text { [C05107] }\end{array}$ & 30.9 & 42 & $9.9 * *$ & 35.5 & 31 & $5.4 *$ & 14.3 & 35 & 3.7 \\
\hline $\begin{array}{c}\text { CG7845 } \\
{\left[\text { [EMS-Mod4] }^{1}\right.}\end{array}$ & 11.1 & 9 & $4.0 \times 10^{-3}$ & 5.6 & 18 & $5.2 *$ & - & - & - \\
\hline $\begin{array}{c}\text { chif } \\
\text { [BG02820] }\end{array}$ & 14.3 & 14 & 0.5 & 6.3 & 16 & $4.4 *$ & - & - & - \\
\hline Fhos[A055] & 19.0 & 21 & 2.3 & 8.3 & 12 & 2.6 & - & - & - \\
\hline $\begin{array}{l}\text { Fkbp13 } \\
\text { [P962] }\end{array}$ & 21.4 & 14 & 3.6 & 11.1 & 9 & 1.0 & - & - & - \\
\hline Grh[IM] & 25.0 & 24 & $5.8 *$ & 13.0 & 23 & 0.4 & 10.0 & 20 & 1.2 \\
\hline Lis1 [k11702] & 17.8 & 28 & 1.8 & 31.2 & 16 & 3.3 & 7.7 & 13 & 0.3 \\
\hline Lis 1 [k13209] $^{2}$ & 30.3 & 33 & $9.5^{* *}$ & 33.3 & 12 & $4.3^{*}$ & 37.5 & 16 & $23.7^{* * *}$ \\
\hline Lis1[k13209] & 33.3 & 12 & $11.8^{* * *}$ & 11.1 & 9 & 1.0 & 28.6 & 14 & $15.5^{* * *}$ \\
\hline$m b l[E 27]$ & 34.3 & 35 & $12.5 * * *$ & 21.0 & 38 & 0.2 & 0.0 & 7 & 3.0 \\
\hline $\begin{array}{l}n A c R \alpha-30 D \\
\text { [EY13897] } \\
\end{array}$ & 0.0 & 9 & $7.9 *$ & 12.5 & 8 & 0.5 & - & - & - \\
\hline Nrk[k14301] & 23.7 & 38 & $4.9 *$ & 13.3 & 15 & 0.3 & 0.0 & 7 & 3.0 \\
\hline $\begin{array}{c}\text { POSH } \\
{[\mathrm{k} 15815]^{2}}\end{array}$ & 9.1 & 22 & $5.0 \times 10^{-3}$ & 21.7 & 23 & 0.3 & - & - & - \\
\hline $\begin{array}{c}\text { Rack1 } \\
{\left[\text { [EY00128] }{ }^{2}\right.} \\
\end{array}$ & 0.0 & 13 & $7.9 *$ & 21.7 & 23 & 0.3 & - & - & - \\
\hline robo[2] & 9.1 & 11 & $4.0 \times 10^{-3}$ & 26.1 & 23 & 1.3 & - & - & - \\
\hline $\begin{array}{c}\text { SP2353 } \\
\text { [MB00605] }\end{array}$ & 5.0 & 20 & 1.0 & 22.2 & 18 & 0.3 & - & - & - \\
\hline $\begin{array}{c}\text { vimar } \\
\text { [EY09646] }\end{array}$ & 21.4 & 42 & 3.6 & 27.3 & 22 & 1.7 & - & - & - \\
\hline
\end{tabular}

all mutant alleles were obtained from BDSC, all RNAi mutants - from VDRC, ${ }^{1}$ - described previously [70], ${ }^{2}$ - from DGRC

- compares to Oregon $R$

in DFNB31 deficient people and mouse whirlin, that causes deafness in the whirler mouse [51]. Hearing loss has been as well demonstrated in association with various forms of muscular dystrophy [51]. Vimar has been shown to regulate mitochondrial function via an increase in citrate synthase activity [52].

$\mathrm{Mbl}$ is a Drosophila homologue of the human gene MBNL1. Mutations of this gene cause myotonic dystrophy and are associated with the RNA toxicity of CUG expansion diseases protein [53]. Here we show that Mbl deficiency results in similar phenotypes to Dys and Dg loss of function, and to specifically interact with Dys in axon projections which is in accord with the Dys specific interaction seen in muscle [35]. Dys has multiple isoforms, and the variability of DMD patients to have mental impairment has been linked in part to small Dys isoform mutations, which leads to speculation that Dys is a target for $\mathrm{Mbl}$ mediated splicing.

Interestingly, $\mathrm{Mbl}$ isoforms have been demonstrated to regulate splicing of $\alpha$-actinin [54], which belongs to the spectrin gene superfamily that also includes dystrophins. $\alpha$-actinin and Capt, the Drosophila homologue of 


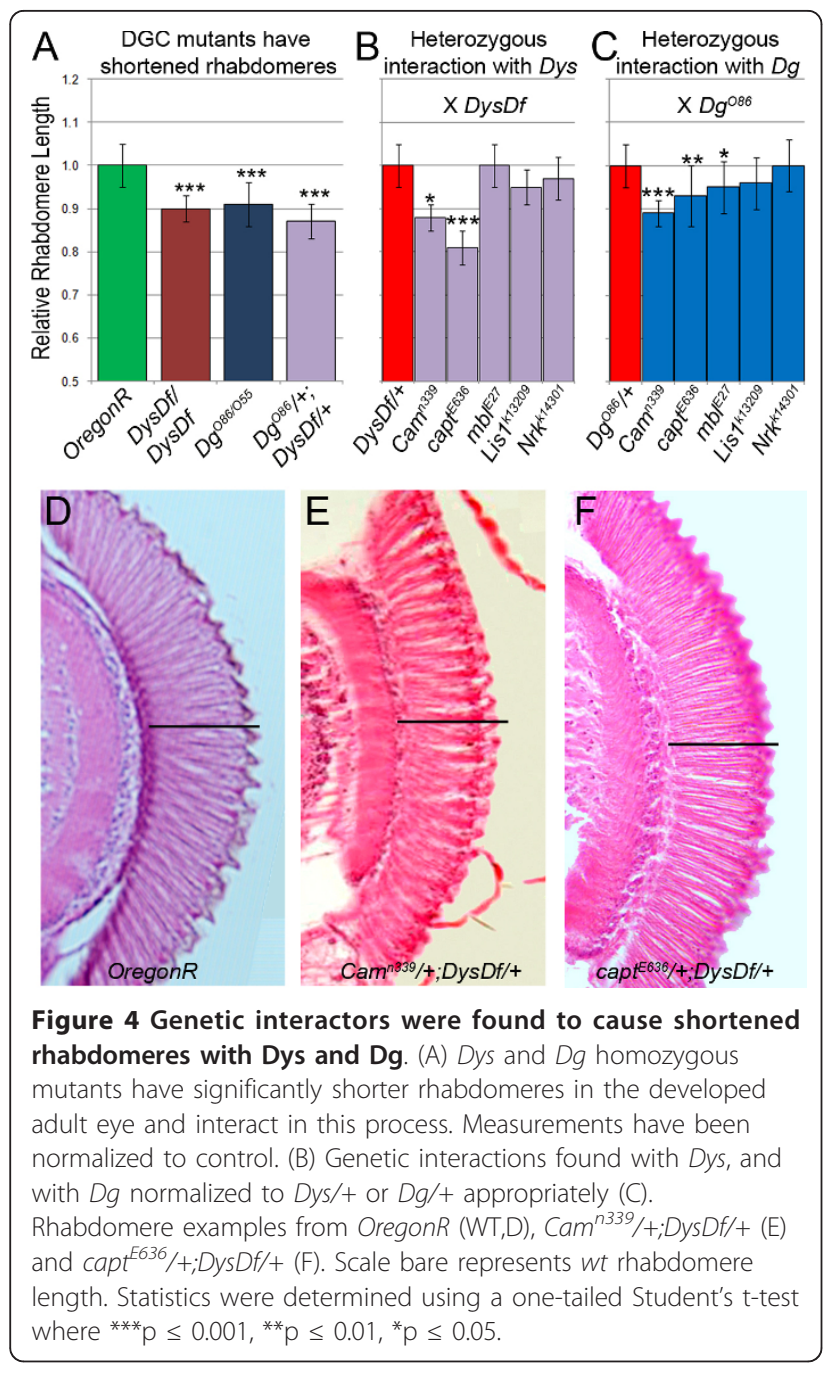

Cyclase-associated protein (CAP) are actin-binding proteins in the growth cone. Capt was first identified in yeast and is highly conserved throughout eukaryotic evolution [55]. The main known function of Capt is to act in the process of actin recycling by working in conjunction with Actin Depolymerization Factor (ADF a.k.a. Cofilin) to help displace Cofilin from G-actin during depolymerization [56,57]. It has already been reported that ADF/Cofilin has a role in retinal elongation [58]. The actin cytoskeleton is a major internal structure that defines the morphology of neurons, and Capt has already been shown to be required to maintain PNS neuronal dendrite homeostasis in Drosophila via kinesin-mediated transport [59]. Additionally, Capt has been found to lead to excessive actin filament polymerization in the eye disc and to cause premature differentiation of photoreceptors [60]. The rate of axon projection is much slower than the rate of microtubule polymerization during axonal growth [61], implying that depolymerization/polymerization of actin is important during pathfinding. We have also shown that Capt interacts with Dys and is necessary for proper projection of photoreceptor axons in the developing brain, and when absent, eyes develop with abnormal rhabdomeres. Furthermore, we have demonstrated that $\operatorname{capt}^{\text {RNA } i}$ mutants exhibit overgrowth of photoreceptor axons, and we believe a possible explanation for this is improper turnover of actin (Figure 5A).

Importantly, proteins that can be regulated by $\mathrm{Ca}^{2+}$ to organize actin filament bundles and to promote filament turnover include $\alpha$-actinin and (ADF)/Cofilin, respectively [62-64]. Cam functions as an intracellular $\mathrm{Ca}^{2+}$ sensor, and when $\mathrm{Ca}^{2+}$-Cam was selectively disrupted in a subset of neurons in Drosophila embryos, stalls in axon extension and errors in growth cone guidance resulted [65]. Actin turnover is highly regulated by $\mathrm{Ca}^{2+}$ levels, and many proteins are $\mathrm{Ca}^{2+}$-mediated to regulate motility and axon guidance. Our results and those from prior studies suggest that Cam is a major functional player of $\mathrm{Ca}^{2+}$ regulation in growth cones. Since we show here that mutations in Cam and capt have similar phenotypes in photoreceptor axon pathfinding and rhabdomere development, we postulate that actin dynamics is the link between these two proteins and the

Table 3 Genetic interaction with Dys and $D g$ in rhabdomere elongation

\begin{tabular}{|c|c|c|c|c|c|c|}
\hline Gene name & Relative rhabdomere length & $\mathrm{n}$, analyzed eyes & p-value & Relative rhabdomere length & $\mathrm{n}$, analyzed eyes & $\mathrm{p}$-value \\
\hline & DysDf $\mathrm{x}$ & DysDf $\mathrm{x}$ & DysDf $\mathrm{x}$ & $D g^{086}$ & $D g^{086}$ & $D g^{086}$ \\
\hline OregonR & $1.00 \pm 0.05$ & 6 & - & $1.00 \pm 0.05$ & 20 & - \\
\hline DysDf & $0.89 \pm 0.03$ & 15 & $4.6 \times 10^{-5}$ & $0.80 \pm 0.04$ & 12 & $3.5 \times 10^{-10}$ \\
\hline $\mathrm{Dg}[086]$ & $0.85 \pm 0.04$ & 12 & $4.0 \times 10^{-5}$ & - & - & - \\
\hline $\mathrm{Dg}[055]$ & - & - & - & $0.83 \pm 0.05$ & 15 & $3.7 \times 10^{-9}$ \\
\hline Cam[n339] & $0.88 \pm 0.03$ & 3 & $1.4 \times 10^{-2}$ & $0.89 \pm 0.03$ & 6 & $3.7 \times 10^{-4}$ \\
\hline Capt[E636] & $0.81 \pm 0.04$ & 6 & $5.0 \times 10^{-5}$ & $0.93 \pm 0.07$ & 12 & $1.0 \times 10^{-2}$ \\
\hline$M b \mid[E 27]$ & $1.00 \pm 0.05$ & 6 & 0.5 & $0.95 \pm 0.06$ & 14 & $2.8 \times 10^{-2}$ \\
\hline Nrk[k14301] & $0.97 \pm 0.05$ & 12 & 0.2 & $1.00 \pm 0.06$ & 12 & 0.5 \\
\hline Lis1 [k13209] & $0.95 \pm 0.04$ & 7 & 0.087 & $0.96 \pm 0.06$ & 13 & 0.084 \\
\hline
\end{tabular}




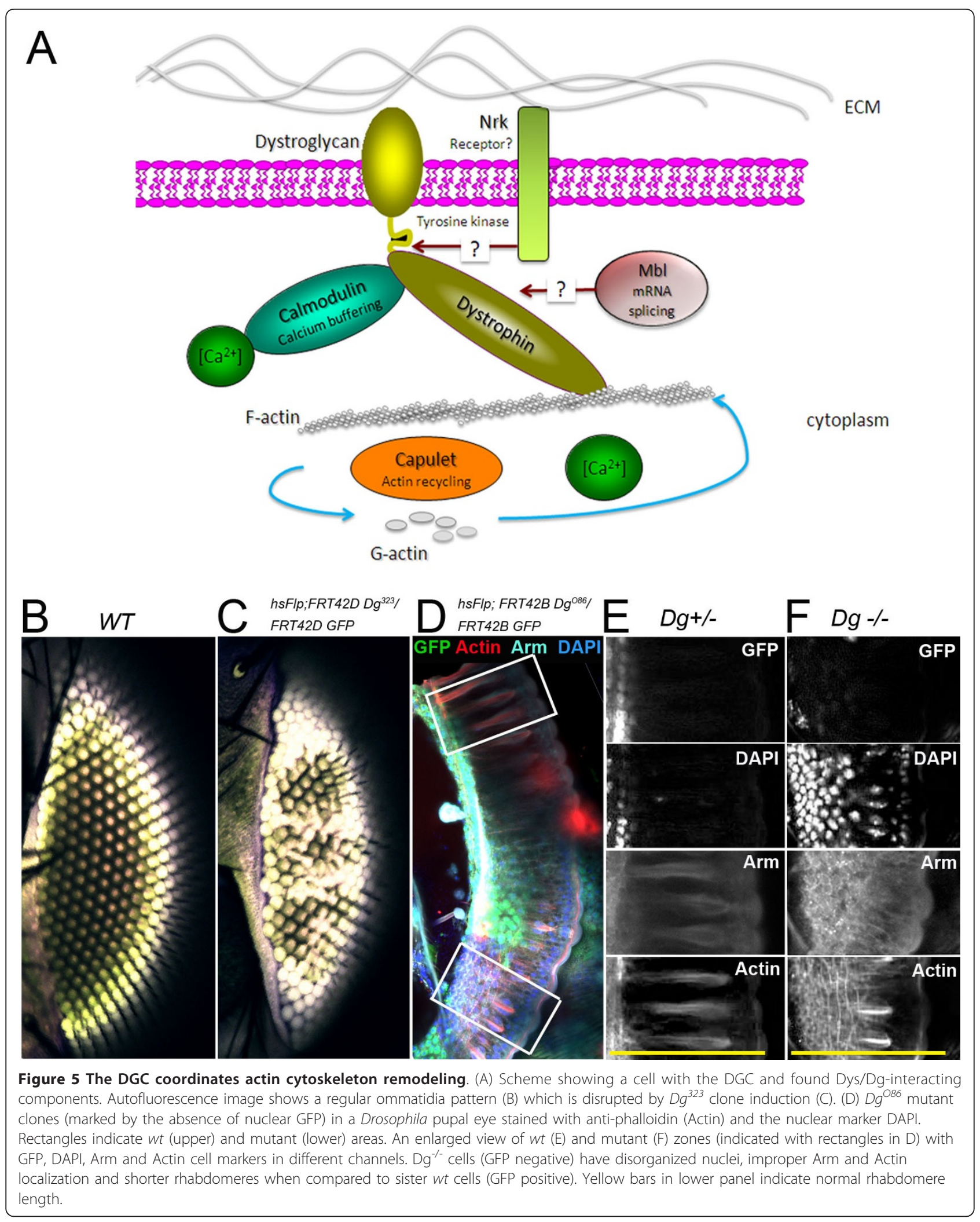


phenotypes described here. Due to the importance of Cam for actin dynamics, its interaction with both Dg and Dys suggests that the DGC coordinates the actin cytoskeleton in the developing eye.

The last gene that we have identified in this work is Nrk. Recently various kinases, channels and other enzymes have been shown to associate with the DGC, although only a few of these interactions have been confirmed in vivo $[66,67]$. Since Nrk is a component found to interact with Dys in photoreceptor axon pathfinding, it is most likely that it functions as a receptor to sense guidance cues rather than as a molecule affecting actin cytoskeletal rearrangement. Our data here hint that Dg and Nrk could be two receptors integral to transferring signals important for neuronal layering.

\section{Conclusions}

Dynamic rearrangement of the actin cytoskeleton is crucial for the central and peripheral nervous system establishment, which depends on proper neuron migration and differentiation. This process requires not only the cell autonomous regulation of neuron motility, but also the interaction between the migrating cell and its underlying substrate. This interaction is often dependent on the signaling transduced via the ECM. The DGC and other factors are believed to be mediators of actin dynamics in growing axons and during neuronal cell morphogenesis, and our study found components that interact with Dys and/or Dg in both of these activities (Figure 5A). Additionally, disruption in gene expression of these components results in the same phenotypes seen with Dys and $D g$ mutants in the developing and adult eye. Our data allows us to conclude that the DGC is involved in signaling to cause cytoskeletal rearrangement and actin turnover in growth cones (Figure 5A). Since many cases of muscular dystrophies are associated with mental retardation, we believe that it is important to understand the role of the DGC in axon migration because understanding of this process could aid in finding an adequate therapy for this aspect of the disease's physiology. Since the human brain continues to develop well after gestation, and evidence shows that nerves maintain plasticity throughout an individual's lifespan, therapies could be devised that reverse these defects after birth.

\section{Methods}

\section{Fly Strains and Genetics}

Fly stocks were maintained at $25^{\circ} \mathrm{C}$ on a standard cornmeal-agar diet. Fly strains used in this study are: loss of function mutants $D y s D f, D g^{O 86}, D g^{055}$ [68], $D g^{323}$ [69] GMR-Gal4 and OregonR (wild type). Lines carrying screened mutations include the following alleles:

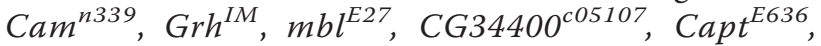

Nrk $^{\text {k14301 }}$, Fkbp13 ${ }^{\text {P962 }}$, vimar ${ }^{\text {EY09646 }}$ Fhos $^{\text {A055 }}$, Lis1 $^{\text {k11702, }}$, Lis1 ${ }^{k 13209}$, FRT42D-Lis ${ }^{\text {k13209 }}$ (Kyoto DGRC), chif ${ }^{B G 02820}$, CG7845 EMS-MOD4 [70], POSH K15815, robo $^{2}$, SP2353 ${ }^{\text {MB00605 }}$, nAcR $\alpha-30 D^{\text {Ey13897 }}$, Rack1 $1^{\text {EY00128. Unless }}$ otherwise stated, lines were obtained from BDRC. RNA $i$ lines were obtained from the VDRC and line numbers are as follows: Cam (v28242), capt (v21995 and v101588), CG34400 (v28945), Fkbp13 (v12863), Lis1 (v106777), mbl (v28731), Nrk (v36282), Rack1 (v104470), robo (v4329), vimar (v21686), POSH (v26655) and Grh (v33679). To determine protein expression of Capt and Cam we obtained GFP protein trap lines from the FlyTrap project [71] that generates a fused GFP protein $\left(\mathrm{Cam}^{\mathrm{PO0695}}\right)$ or GFP expression is controlled by enhancer elements (capt $\left.{ }^{Y B O 070}\right)$.

Homozygous lethal lines were balanced over the $\mathrm{CyO}$ balancer chromosome marked with Kruppel-GFP to make it possible to determine the genotypes of larvae. Third chromosome alleles were balanced with the TM6, $\mathrm{Tb}$ balancer chromosome which results in shorter and thicker larvae allowing for its detection. Non-GFP and non- $\mathrm{Tb}$ progeny (F1) were collected from crosses at the L3 larval stage of development for axon path-finding analysis and as adult flies for retina length determination.

$D g$ mutant clonal cells were generated by crossing females of genotype hsFlp; FRT $42 B$ GFP/CyO with males of genotype $F R T 42 B \mathrm{Dg}^{\mathrm{O} 6} / \mathrm{CyO}$. Vials were exposed to $2 \mathrm{hrs}$ of $37^{\circ} \mathrm{C}$ heat shocks per day starting 1 day AEL until pupae formation. Dissection of eyes was done approximately $70 \mathrm{hrs}$ APF.

\section{Immunohistochemistry}

Dissections were done in PBS, fixed in 4\% formaldehyde and antibodies were applied as described previously [24]. The following antibodies were used: mouse anti24B10 (1:50, Development Studies Hybridoma Bank), rabbit anti-Dg [69] (1:1000), anti-Dp186 and anti-Dys$\mathrm{CO}_{2} \mathrm{H}$ [28] (1:600), anti-Arm, Alexa 488 and 568 goat anti-mouse, Alexa 488 goat anti-rabbit (1:500, Molecular probes) and Alexa 568 conjugated phalloidin (1:40, Invitrogen). DAPI was used to visualize nuclei. Samples were mounted on slides in 70\% glycerol, $2 \%$ NPG, $1 \mathrm{X}$ PBS and analyzed using a confocal microscopes (Leica TCS SP5, Zeiss Axio Imager).

\section{Histology}

For analysis of eye and head morphology, $10 \mu \mathrm{m}$ paraffin-embedded sections were cut of fly heads. In order to prepare Drosophila sections, fly heads were immobilized in collars in the required orientation and fixed in Carnoy fixative solution (6:3:1 Ethanol:Chloroform:Acetic acid) at $4^{\circ} \mathrm{C}$ overnight. Tissue dehydration and embedding in paraffin was performed as described previously 
[72]. Histological sections were prepared using a Hyrax M25 (Zeiss) microtome and stained with hematoxylin and eosin. All chemicals for these procedures were obtained from Sigma Aldrich. Analysis was done using a light microscope (Zeiss). To prepare Drosophila adult brain cryosections the protocol adapted from [72] was used. First flies were located in collars and immediately frozen in TissueTek ${ }^{\circledR}$ O.C.T. (Tissue-Tek) at $\approx-40^{\circ} \mathrm{C}$. Then frozen heads were sectioned on a cryo-microtom Leica CM3050S with a section thickness of $10 \mu \mathrm{m}$. Fixation was carried out in $4 \%$ formaldehyde (Polyscience, Inc.) for $10 \mathrm{~min}$ at room temperature.

\section{Data Analysis}

The percentage of larval brain lobes with abnormalities in the lamina plexus were quantified as the percentage of defective lobes divided by the total lobes examined. Adult ommatidia lengths were measured and normalized to the appropriate control.

\section{Statistics}

Statistical analysis of abnormal lamina plexus formation was done using a one-tailed $\chi^{2}$ test. Statistical analysis of ommatidia length was done using a one-tailed Student's t-test where error bars represent the average deviation. For transheterozygous interation of screened genes with $D y s$ and $D g$ comparisons were made to Dys/ + or $D g /+$ as appropriate.

\section{Abbreviations}

DGC: Dystrophin Glycoprotein Complex; Dys: Dystrophin; Dg: Dystroglycan; MD: muscular Dystrophy

\section{Author details \\ ${ }^{1}$ Max Planck Institute for biophysical chemistry, Research group of Gene Expression and Signaling, Am Fassberg 11, 37077, Goettingen, Germany. ${ }^{2}$ Ivan Franko National University of Lviv, Department of Genetics and Biotechnology, Hrushevsky 4, 79005, Ukraine.}

\section{Authors' contributions}

AKM, MMK and VMR carried out all immunohistochemistry and histological experiments. AKM, MMK and HRS participated in the design of the study and drafted the manuscript. All authors read and approved the final manuscript.

Received: 19 April 2011 Accepted: 26 September 2011

Published: 26 September 2011

\section{References}

1. Lim LE, Campbell KP: The sarcoglycan complex in limb-girdle muscular dystrophy. Curr Opin Neurol 1998, 11(5):443-452.

2. Matsumura K, Campbell KP: Dystrophin-glycoprotein complex: its role in the molecular pathogenesis of muscular dystrophies. Muscle Nerve 1994, 17(1):2-15.

3. Hayashi YK, Chou FL, Engvall E, Ogawa M, Matsuda C, Hirabayashi S, Yokochi K, Ziober BL, Kramer RH, Kaufman SJ, Ozawa E, Goto Y, Nonaka I, Tsukahara T, Wang JZ, Hoffman EP, Arahata K: Mutations in the integrin alpha7 gene cause congenital myopathy. Nat Genet 1998, 19(1):94-97.
4. Billard C, Gillet P, Signoret JL, Uicaut E, Bertrand P, Fardeau M, BarthezCarpentier MA, Santini JJ: Cognitive functions in Duchenne muscular dystrophy: a reappraisal and comparison with spinal muscular atrophy. Neuromuscul Disord 1992, 2(5-6):371-378.

5. Perronnet C, Vaillend C: Dystrophins, utrophins, and associated scaffolding complexes: role in mammalian brain and implications for therapeutic strategies. J Biomed Biotechnol 2010, 2010:849426.

6. Kanagawa M, Toda T: The genetic and molecular basis of muscular dystrophy: roles of cell-matrix linkage in the pathogenesis. J Hum Genet 2006, 51(11):915-926

7. Sciandra F, Bozzi M, Bianchi M, Pavoni E, Giardina B, Brancaccio A: Dystroglycan and muscular dystrophies related to the dystrophinglycoprotein complex. Ann Ist Super Sanita 2003, 39(2):173-181.

8. Montanaro F, Carbonetto S: Targeting dystroglycan in the brain. Neuron 2003, 37(2):193-196.

9. Olson EC, Walsh CA: Smooth, rough and upside-down neocortical development. Curr Opin Genet Dev 2002, 12(3):320-327.

10. Kobayashi K, Nakahori $Y$, Miyake M, Matsumura K, Kondo-lida E, Nomura $Y$, Segawa M, Yoshioka M, Saito K, Osawa M, Hamano K, Sakakihara Y, Nonaka I, Nakagome Y, Kanazawa I, Nakamura Y, Tokunaga K, Toda T: An ancient retrotransposal insertion causes Fukuyama-type congenital muscular dystrophy. Nature 1998, 394(6691):388-392.

11. Yoshida A, Kobayashi K, Manya H, Taniguchi K, Kano H, Mizuno M, Inazu T, Mitsuhashi H, Takahashi S, Takeuchi M, Herrmann R, Straub V, Talim B, Voit T, Topaloglu H, Toda T, Endo T: Muscular dystrophy and neuronal migration disorder caused by mutations in a glycosyltransferase, POMGnT1. Dev Cell 2001, 1(5):717-724.

12. Beltran-Valero de Bernabe D, Currier S, Steinbrecher A, Celli J, van Beusekom E, van der Zwaag B, Kayserili H, Merlini L, Chitayat D, Dobyns WB, Cormand B, Lehesjoki AE, Cruces J, Voit T, Walsh CA, van Bokhoven H, Brunner HG: Mutations in the O-mannosyltransferase gene POMT1 give rise to the severe neuronal migration disorder Walker-Warburg syndrome. Am J Hum Genet 2002, 71(5):1033-1043.

13. Beltran-Valero de Bernabe D, Voit T, Longman C, Steinbrecher A, Straub V, Yuva Y, Herrmann R, Sperner J, Korenke C, Diesen C, Dobyns WB, Brunner $\mathrm{HG}$, van Bokhoven $\mathrm{H}$, Brockington M, Muntoni F: Mutations in the FKRP gene can cause muscle-eye-brain disease and Walker-Warburg syndrome. J Med Genet 2004, 41(5):e61.

14. Barresi R, Michele DE, Kanagawa M, Harper HA, Dovico SA, Satz JS, Moore SA, Zhang W, Schachter H, Dumanski JP, Cohn RD, Nishino I, Campbell KP: LARGE can functionally bypass alpha-dystroglycan glycosylation defects in distinct congenital muscular dystrophies. Nat Med 2004, 10(7):696-703.

15. van Reeuwijk J, Brunner HG, van Bokhoven H: Glyc-O-genetics of WalkerWarburg syndrome. Clin Genet 2005, 67(4):281-289.

16. van Reeuwijk J, Grewal PK, Salih MA, Beltran-Valero de Bernabe D, McLaughlan JM, Michielse CB, Herrmann R, Hewitt JE, Steinbrecher A, Seidahmed MZ, Shaheed MM, Abomelha A, Brunner HG, van Bokhoven $H$, Voit T: Intragenic deletion in the LARGE gene causes Walker-Warburg syndrome. Hum Genet 2007, 121(6):685-690.

17. Clement E, Mercuri E, Godfrey C, Smith J, Robb S, Kinali M, Straub V, Bushby K, Manzur A, Talim B, Cowan F, Quinlivan R, Klein A, Longman C, McWilliam R, Topaloglu H, Mein R, Abbs S, North K, Barkovich AJ, Rutherford M, Muntoni F: Brain involvement in muscular dystrophies with defective dystroglycan glycosylation. Ann Neurol 2008, 64(5):573-582.

18. Godfrey C, Clement E, Mein R, Brockington M, Smith J, Talim B, Straub V, Robb S, Quinlivan R, Feng L, Jimenez-Mallebrera C, Mercuri E, Manzur AY, Kinali M, Torelli S, Brown SC, Sewry CA, Bushby K, Topaloglu H, North K, Abbs S, Muntoni F: Refining genotype phenotype correlations in muscular dystrophies with defective glycosylation of dystroglycan. Brain 2007, 130(Pt 10):2725-2735.

19. Pillers DA, Weleber RG, Woodward WR, Green DG, Chapman VM, Ray PN: mdxCv3 mouse is a model for electroretinography of Duchenne/Becker muscular dystrophy. Invest Ophthalmol Vis Sci 1995, 36(2):462-466.

20. Cibis GW, Fitzgerald KM, Harris DJ, Rothberg PG, Rupani M: The effects of dystrophin gene mutations on the ERG in mice and humans. Invest Ophthalmol Vis Sci 1993, 34(13):3646-3652.

21. Pillers DA, Bulman DE, Weleber RG, Sigesmund DA, Musarella MA, Powell BR, Murphey WH, Westall C, Panton C, Becker LE, et al: Dystrophin 
expression in the human retina is required for normal function as defined by electroretinography. Nat Genet 1993, 4(1):82-86.

22. Cox GA, Phelps SF, Chapman VM, Chamberlain JS: New mdx mutation disrupts expression of muscle and nonmuscle isoforms of dystrophin. Nat Genet 1993, 4(1):87-93.

23. van der Plas MC, Pilgram GS, de Jong AW, Bansraj MR, Fradkin LG, Noordermeer JN: Drosophila Dystrophin is required for integrity of the musculature. Mech Dev 2007, 124(7-8):617-630.

24. Shcherbata HR, Yatsenko AS, Patterson L, Sood VD, Nudel U, Yaffe D, Baker D, Ruohola-Baker H: Dissecting muscle and neuronal disorders in a Drosophila model of muscular dystrophy. EMBO J 2007, 26(2):481-493.

25. Taghli-Lamallem O, Akasaka T, Hogg G, Nudel U, Yaffe D, Chamberlain JS, Ocorr K, Bodmer R: Dystrophin deficiency in Drosophila reduces lifespan and causes a dilated cardiomyopathy phenotype. Aging Cell 2008, 7(2):237-249.

26. Campbell KP: Three muscular dystrophies: loss of cytoskeletonextracellular matrix linkage. Cell 1995, 80(5):675-679.

27. Greener MJ, Roberts RG: Conservation of components of the dystrophin complex in Drosophila. FEBS Lett 2000, 482(1-2):13-18.

28. van der Plas MC, Pilgram GS, Plomp JJ, de JA, Fradkin LG, Noordermeer JN: Dystrophin is required for appropriate retrograde control of neurotransmitter release at the Drosophila neuromuscular junction. $J$ Neurosci 2006, 26(1):333-344.

29. Wairkar YP, Fradkin LG, Noordermeer JN, DiAntonio A: Synaptic defects in a Drosophila model of congenital muscular dystrophy. J Neurosci 2008, 28(14):3781-3789.

30. Fradkin LG, Baines RA, van der Plas MC, Noordermeer JN: The dystrophin Dp186 isoform regulates neurotransmitter release at a central synapse in Drosophila. J Neurosci 2008, 28(19):5105-5114.

31. Bogdanik L, Framery B, Frolich A, Franco B, Mornet D, Bockaert J, Sigrist SJ, Grau Y, Parmentier ML: Muscle dystroglycan organizes the postsynapse and regulates presynaptic neurotransmitter release at the Drosophila neuromuscular junction. PLoS One 2008, 3(4):e2084.

32. Marrone AK, Kucherenko MM, Wiek R, Gopfert MC, Shcherbata HR: Hyperthermic seizures and aberrant cellular homeostasis in Drosophila dystrophic muscles. Sci Rep 2011, 1.

33. Zhan Y, Melian NY, Pantoja M, Haines N, Ruohola-Baker H, Bourque CW, Rao Y, Carbonetto S: Dystroglycan and mitochondrial ribosomal protein I34 regulate differentiation in the Drosophila eye. PLoS One 2010, 5(5): e10488.

34. Moore SA, Saito F, Chen J, Michele DE, Henry MD, Messing A, Cohn RD, Ross-Barta SE, Westra S, Williamson RA, Hoshi T, Campbell KP: Deletion of brain dystroglycan recapitulates aspects of congenital muscular dystrophy. Nature 2002, 418(6896):422-425.

35. Kucherenko MM, Marrone AK, Rishko VM, Magliarelli Hde F, Shcherbata HR Stress and muscular dystrophy: a genetic screen for dystroglycan and dystrophin interactors in Drosophila identifies cellular stress response components. Dev Biol 2011, 352(2):228-242.

36. Lei $Y$, Warrior R: The Drosophila Lissencephaly1 (DLis1) gene is required for nuclear migration. Dev Biol 2000, 226(1):57-72.

37. Begemann G, Paricio N, Artero R, Kiss I, Perez-Alonso M, Mlodzik M: muscleblind, a gene required for photoreceptor differentiation in Drosophila, encodes novel nuclear Cys3His-type zinc-finger-containing proteins. Development 1997, 124(21):4321-4331.

38. UV AE, Harrison EJ, Bray SJ: Tissue-specific splicing and functions of the Drosophila transcription factor Grainyhead. Mol Cell Biol 1997, 17(11):6727-6735.

39. Oishi I, Sugiyama S, Liu ZJ, Yamamura H, Nishida Y, Minami Y: A novel Drosophila receptor tyrosine kinase expressed specifically in the nervous system. Unique structural features and implication in developmental signaling. J Biol Chem 1997, 272(18):11916-11923.

40. Lo PC, Frasch M: bagpipe-Dependent expression of vimar, a novel Armadillo-repeats gene, in Drosophila visceral mesoderm. Mech Dev 1998, 72(1-2):65-75.

41. Kidd T, Brose K, Mitchell KJ, Fetter RD, Tessier-Lavigne M, Goodman CS, Tear G: Roundabout controls axon crossing of the CNS midline and defines a novel subfamily of evolutionarily conserved guidance receptors. Cell 1998, 92(2):205-215.

42. Pappu KS, Morey M, Nern A, Spitzweck B, Dickson BJ, Zipursky SL: Robo-3mediated repulsive interactions guide $\mathrm{R} 8$ axons during Drosophila visual system development. Proc Natl Acad Sci USA 2011, 108(18):7571-7576.
43. Seeger M, Tear G, Ferres-Marco D, Goodman CS: Mutations affecting growth cone guidance in Drosophila: genes necessary for guidance toward or away from the midline. Neuron 1993, 10(3):409-426.

44. Tayler TD, Robichaux MB, Garrity PA: Compartmentalization of visual centers in the Drosophila brain requires Slit and Robo proteins. Development 2004, 131(23):5935-5945.

45. Daines B, Wang H, Wang L, Li Y, Han Y, Emmert D, Gelbart W, Wang X, Li W, Gibbs R, Chen R: The Drosophila melanogaster transcriptome by paired-end RNA sequencing. Genome Res 2011, 21(2):315-324.

46. Landis $\mathrm{G}$, Tower J: The Drosophila chiffon gene is required for chorion gene amplification, and is related to the yeast Dbf4 regulator of DNA replication and cell cycle. Development 1999, 126(19):4281-4293.

47. Sasaki S, Shionoya A, Ishida M, Gambello MJ, Yingling J, Wynshaw-Boris A Hirotsune S: A LIS1/NUDEL/cytoplasmic dynein heavy chain complex in the developing and adult nervous system. Neuron 2000, 28(3):681-696.

48. Wynshaw-Boris A: Lissencephaly and LIS1: insights into the molecular mechanisms of neuronal migration and development. Clin Genet 2007, 72(4):296-304.

49. Huze C, Bauche S, Richard P, Chevessier F, Goillot E, Gaudon K, Ben Ammar A, Chaboud A, Grosjean I, Lecuyer HA, Bernard V, Rouche A, Alexandri N, Kuntzer T, Fardeau M, Fournier E, Brancaccio A, Ruegg MA, Koenig J, Eymard B, Schaeffer L, Hantai D: Identification of an agrin mutation that causes congenital myasthenia and affects synapse function. Am J Hum Genet 2009, 85(2):155-167.

50. Sato S, Omori Y, Katoh K, Kondo M, Kanagawa M, Miyata K, Funabiki K, Koyasu T, Kajimura N, Miyoshi T, Sawai H, Kobayashi K, Tani A, Toda T, Usukura J, Tano Y, Fujikado T, Furukawa T: Pikachurin, a dystroglycan ligand, is essential for photoreceptor ribbon synapse formation. Nat Neurosci 2008, 11(8):923-931.

51. Mburu P, Mustapha M, Varela A, Weil D, El-Amraoui A, Holme RH, Rump A Hardisty RE, Blanchard S, Coimbra RS, Perfettini I, Parkinson N, Mallon AM, Glenister P, Rogers MJ, Paige AJ, Moir L, Clay J, Rosenthal A, Liu XZ, Blanco G, Steel KP, Petit C, Brown SD: Defects in whirlin, a PDZ domain molecule involved in stereocilia elongation, cause deafness in the whirler mouse and families with DFNB31. Nat Genet 2003, 34(4):421-428.

52. Chen J, Shi X, Padmanabhan R, Wang Q, Wu Z, Stevenson SC, Hild M, Garza D, Li H: Identification of novel modulators of mitochondrial function by a genome-wide RNAi screen in Drosophila melanogaster. Genome Res 2008, 18(1):123-136.

53. Paul S, Dansithong W, Kim D, Rossi J, Webster NJ, Comai L, Reddy S: Interaction of muscleblind, CUG-BP1 and hnRNP H proteins in DM1associated aberrant IR splicing. Embo J 2006, 25(18):4271-4283.

54. Vicente M, Monferrer L, Poulos MG, Houseley J, Monckton DG, O'Dell KM, Swanson MS, Artero RD: Muscleblind isoforms are functionally distinct and regulate alpha-actinin splicing. Differentiation 2007, 75(5):427-440.

55. Hubberstey AV, Mottillo EP: Cyclase-associated proteins: CAPacity for linking signal transduction and actin polymerization. Faseb J 2002, 16(6):487-499

56. Balcer HI, Goodman AL, Rodal AA, Smith E, Kugler J, Heuser JE, Goode BL: Coordinated regulation of actin filament turnover by a high-molecularweight Srv2/CAP complex, cofilin, profilin, and Aip1. Curr Biol 2003, 13(24):2159-2169.

57. Moriyama K, Yahara I: Human CAP1 is a key factor in the recycling of cofilin and actin for rapid actin turnover. J Cell Sci 2002, 115(Pt 8):1591-1601.

58. Pham $H, Y u H$, Laski FA: Cofilin/ADF is required for retinal elongation and morphogenesis of the Drosophila rhabdomere. Dev Biol 2008, 318(1):82-91.

59. Medina PM, Worthen RJ, Forsberg $L$, Brenman JE: The actin-binding protein capulet genetically interacts with the microtubule motor kinesin to maintain neuronal dendrite homeostasis. PLoS One 2008, 3(8):e3054.

60. Benlali A, Draskovic I, Hazelett DJ, Treisman JE: act up controls actin polymerization to alter cell shape and restrict Hedgehog signaling in the Drosophila eye disc. Cell 2000, 101(3):271-281.

61. Schulze $E$, Kirschner M: New features of microtubule behaviour observed in vivo. Nature 1988, 334(6180):356-359.

62. Fukushima N, Ishii I, Habara Y, Allen CB, Chun J: Dual regulation of actin rearrangement through lysophosphatidic acid receptor in neuroblast cell lines: actin depolymerization by $\mathrm{Ca}(2+)$-alpha-actinin and polymerization by rho. Mol Biol Cell 2002, 13(8):2692-2705. 
63. Lu M, Witke W, Kwiatkowski DJ, Kosik KS: Delayed retraction of filopodia in gelsolin null mice. J Cell Biol 1997, 138(6):1279-1287.

64. Sarmiere PD, Bamburg JR: Regulation of the neuronal actin cytoskeleton by ADF/cofilin. J Neurobiol 2004, 58(1):103-117.

65. VanBerkum MF, Goodman CS: Targeted disruption of $\mathrm{Ca}(2+)$-calmodulin signaling in Drosophila growth cones leads to stalls in axon extension and errors in axon guidance. Neuron 1995, 14(1):43-56.

66. Pilgram GS, Potikanond S, Baines RA, Fradkin LG, Noordermeer JN: The roles of the dystrophin-associated glycoprotein complex at the synapse. Mol Neurobiol 2010, 41(1):1-21.

67. Adams ME, Tesch Y, Percival JM, Albrecht DE, Conhaim Jl, Anderson $\mathrm{K}$, Froehner SC: Differential targeting of nNOS and AQP4 to dystrophindeficient sarcolemma by membrane-directed alpha-dystrobrevin. I Cell Sci 2008, 121(Pt 1):48-54

68. Christoforou CP, Greer CE, Challoner BR, Charizanos D, Ray RP: The detached locus encodes Drosophila Dystrophin, which acts with other components of the Dystrophin Associated Protein Complex to influence intercellular signalling in developing wing veins. Dev Biol 2008, 313(2):519-532.

69. Deng WM, Schneider M, Frock R, Castillejo-Lopez C, Gaman EA, Baumgartner S, Ruohola-Baker H: Dystroglycan is required for polarizing the epithelial cells and the oocyte in Drosophila. Development 2003, 130(1):173-184.

70. Kucherenko MM, Pantoja M, Yatsenko AS, Shcherbata HR, Fischer KA, Maksymiv DV, Chernyk YI, Ruohola-Baker H: Genetic modifier screens reveal new components that interact with the Drosophila dystroglycandystrophin complex. PLoS One 2008, 3(6):e2418.

71. Quinones-Coello AT, Petrella LN, Ayers K, Melillo A, Mazzalupo S, Hudson AM, Wang S, Castiblanco C, Buszczak M, Hoskins RA, Cooley L: Exploring strategies for protein trapping in Drosophila. Genetics 2007, 175(3):1089-1104.

72. Kucherenko M, Marrone A, Rishko V, Yatsenko A, Klepzig A, Shcherbata H: Paraffin-embedded and Frozen Sections of Drosophila Adult Muscles. JOVE 2010.

doi:10.1186/1471-2202-12-93

Cite this article as: Marrone et al.: New Dystrophin/Dystroglycan

interactors control neuron behavior in Drosophila eye. BMC Neuroscience 2011 12:93.

\section{Submit your next manuscript to BioMed Central and take full advantage of:}

- Convenient online submission

- Thorough peer review

- No space constraints or color figure charges

- Immediate publication on acceptance

- Inclusion in PubMed, CAS, Scopus and Google Scholar

- Research which is freely available for redistribution

Submit your manuscript at www.biomedcentral.com/submit 